\title{
Palmitvaccenic acid ( $\Delta 11$-cis-hexadecenoic acid) is synthesized by an OLE1-like desaturase in the arbuscular mycorrhiza fungus Rhizophagus irregularis
}

Mathias Brands ${ }^{1}$, Edgar B. Cahoon ${ }^{2}$ and Peter Dörmann ${ }^{1}$

${ }^{1}$ University of Bonn, Institute of Molecular Physiology and Biotechnology of Plants (IMBIO), Karlrobert-Kreiten-Straße 13, 53115 Bonn, Germany

${ }^{2}$ University of Nebraska, Center for Plant Science Information, E318 Beadle Center, 1901

Vine St., Lincoln NE 68588, USA

Correspondence: Peter Dörmann (doermann@uni-bonn.de), phone: 049228732830

Key words: Rhizophagus irregularis, arbuscular mycorrhiza fungi, colonization, biomarker, desaturase, palmitvaccenic acid

Running title: Palmitvaccenic acid synthesis in arbuscular mycorrhiza fungi

\section{Abstract}

Arbuscular mycorrhiza (AM) fungi deliver mineral nutrients to the plant host in exchange for reduced carbon in the form of sugars and lipids. Colonization with AM fungi upregulates a specific host lipid synthesis pathway resulting in the production of fatty acids. The fungus Rhizophagus irregularis accumulates predominantly palmitic acid (16:0) and the unusual palmitvaccenic acid (16:1 $\left.{ }^{\Delta 11 c i s}\right)$. Here, we present the isolation and characterization of RIOLE1-LIKE, the desaturase involved in palmitvaccenic acid synthesis, by heterologous expression in yeast and plants. Results are in line with the scenario that RIOLE1-LIKE encodes an acyl-CoA desaturase with substrate specificity for C15-C18 acyl groups, in particular C16. Phylogenetic analysis of RiOLE1-LIKE related sequences revealed that this gene is conserved in AM fungi from the Glomales and Diversisporales, but is absent from non-symbiotic Mortierellaceae and Mucoromycotina fungi, suggesting that $16: 1^{\Delta 11 \text { cis }}$ provides a specific function during AM colonization. 


\section{Introduction}

Mycorrhiza fungi establish symbiotic interactions with plant roots. The fungi provide mineral nutrients, particularly phosphate, to the host, in exchange for reduced carbon [1]. AM fungi establish an intricate membrane system in the cytosol of the root cortex cell, the so-called arbuscule, where nutrient and carbon exchange takes place [2]. Previously, it was believed that carbon is transported to the fungus solely in the form of carbohydrates. The fact that AM fungi lack the genes for fatty acid de novo synthesis, together with recent evidence that plant-derived fatty acids accumulate in the fungus, demonstrated that in addition to carbohydrates, fatty acid-containing lipids are transferred from the plant to the fungus [3-6]. In line with this scenario, expression of host specific genes (e.g. DIS, FatM, RAM2) involved in fatty acid and lipid synthesis is upregulated during colonization. The DIS gene encodes plastidial $\beta$-keotacyl-acyl carrierer (ACP) synthase I (KASI) involved in the production of palmitoyl-(16:0)-ACP [6]. FatM encodes a plastidial acyl-ACP thioesterase, with high activity for hydrolysis of 16:0-ACP $[7,8]$. After export from the plastids, fatty acids are converted into acyl-CoA thioesters. The RAM2 gene product produces sn2-acyl-glycerol form glycerol-3phosphate and acyl-CoA, with preference for 16:0-CoA [3]. Recently, methyl-myristic acid (methyl-14:0) was shown to induce spore formation of $R$. irregularis [9]. Furthermore, myristic acid (14:0) supplementation to the medium was sufficient to support hyphal growth in axenic culture, 14:0 was taken up by the fungus and metabolized [10]. Taken together, these results suggest that a 14:0 or 16:0-containing lipid most likely is transferred from the host to the fungus where it serves as carbon source in addition to carbohydrates.

While AM fungi genomes lack the genes of fatty acid de novo synthesis, they do contain genes encoding fatty acid desaturases and elongases [4]. Therefore, AM fungi can desaturase and produce very long chain fatty acids from precursors such as 14:0 or 16:0 [11]. The major fatty acids in AMF are 16:0 and 16:1 11 cis (11-cis-palmitvaccenic acid; $\left.16: 1^{\omega 5 c i s}\right) .16: 1^{\Delta 11 \text { cis }}$ is absent from plants. It accounts for $46-78$ mol\% of total fatty acids in spores of AMF of the Glomales including the families Acaulosporaceae, Glomaceae and Gigasporaceae, albeit some species of Glomaceae (Glomus leptotichum, Glomus occultum) and Gigasporacea (Gigaspora albida, Gigaspora gigantea, Gigaspora margarita, Gigaspora rosea) contain no or traces of $16: 1^{\Delta 11 \text { cis }}$. In addition to $16: 1^{\Delta 11 \text { cis }}$, Rhizophagus irregularis, Glomus claroideum and Gigaspora roseae spores and hyphae contain $0.2-3.3$ mol\% of

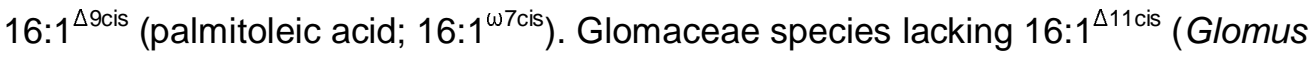
leptotichum, Glomus occultum) instead contain considerable amounts (11 - $55 \%$ of $16: 1^{\Delta 9 c i s}$. Spores of Gigaspora spp. with low amounts of $16: 1^{\Delta 11 \text { cis }}$ contain high contents (38 - $48 \%$ ) of $18: 1^{\Delta 9 c i s}$ (oleic acid) and $8-15 \%$ of $20: 1^{\Delta 11 \text { cis }}$ (gondoic acid) [12]. Oleic acid and gondoic acid are present in low amounts in spores of $R$. irregualris and other Glomaceae [11,12]. 
Palmitoleic acid, oleic acid, and gondoic acid are not AM fungi-specific, because they are found in non-colonized plant roots [11,13]. AM fungi additionally contain C20, C22 and C24 fatty acids. Of these, $20: 3$ is the predominant one with $0.2-1.5 \mathrm{~mol} \%$ in $R$. irregularis $[11,13]$.

$16: 1^{\Delta 11 c i s}$ is only found in AM fungi but is absent from plants and from most other fungi except for low amounts in the ectomycorrhiza fungi Pisolithus tinctorius and Laccaria bicolor [14,15]. 16:1 $1^{\Delta 11 \text { cis }}$ is also found in some bacterial species, including Cytophaga hutchinsonii or Lactobacillus spp. [16,17]. In some moths, 16:1 $1^{\Delta 11 \text { cis }}$ serves as intermediate for the synthesis

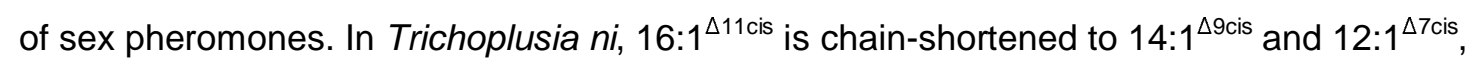
the latter being reduced to the alcohol and acetylated, forming the active pheromone cis-7dodencenyl acetate [18]. In the small ermine moths Yponomeuta evonymella and Y. padella, 11-cis-hexadecenol-acetate is directly used as sex pheromone [19].

In AM fungi, 16:1 ${ }^{\Delta 11 \text { cis }}$ accumulates in different glycerolipids, mostly in the storage lipid triacylglycerol, but it is also found in phospholipids [4,13]. Because of the rather unique presence in AM fungi, 16:1 $1^{\Delta 11 \text { cis }}$ and of other specific fatty acids (e.g. 20:3), these fatty acids were used as lipid biomarkers for AM fungi under laboratory and field conditions [12,20,21]. In line with this scenario, the rate of colonization with $R$. irregularis correlates with the accumulation of 16:1 ${ }^{\Delta 11 \text { cis }}$ in colonized roots [22-24].

The gene involved in 16:1 $1^{\Delta 11 \text { cis }}$ production in AM fungi remained unknown. Evaluation of the $R$. irregularis genome and transcriptome revealed the presence of one sequence (RIOLE1) with high similarity to the Saccharomyces cerevisiae OLE1 (oleic acid dependent1) gene, and a second sequence (RIOLE1-LIKE) with lower similarity [4]. In addition, the $R$. irregularis genome contains five sequences with high similarity to the $\Delta 12$ desaturase, $\Delta 5$ desaturase and $\Delta 6$ desaturase sequences from Mortierella alpina [4]. To identify the gene involved in 16:1 $1^{\Delta 11 \text { cis }}$ production in $R$. irregularis, we focused on the characterization of RIOLE1 and RIOLE1-LIKE. Expression in the S. cerevisiae $\triangle$ ole1 mutant together with fatty acid analysis and fatty acid feeding experiments revealed that RiOLE1 predominantly produces oleic acid $\left(18: 1^{\triangle 9 c i s}\right)$, while RiOLE1-LIKE is crucial for the synthesis of $16: 1^{\Delta 11 \text { cis }}$. RiOLE1-LIKE was subsequently introduced into transgenic tobacco and Camelina, to evaluate its capacity to produce $16: 1^{\Delta 11 \text { cis }}$ in a plant system, and the phylogenetic distribution of RiOLE1-LIKE in symbiotic and non-symbiotic fungi was investigated. 


\section{Experimental}

\section{Phylogenetic analysis}

For retrieving the desaturase sequences from $R$. irregularis, the four characterized Mortierella alpina desaturase sequences were retrieved from UniProtKB (uniprot.org) and used in BLASTp searches at the EnsemblFungi database (fungi.ensembl.org). For phylogenetic analysis of desaturases in symbiotic and non-symbiotic Mucoromycota, RiOLE1 and RiOLE1-LIKE sequences were used in BLASTn searches to identify orthologs in Gigasprora rosea, Rhizophagus cerebriforme and Rhizophagus diaphanus genomes available at MycoCosm [25]. Rhizophagus clarus, Mortierella circinelloides, Rhizophagus microsporus, Mortierella elongata and Lobosporangium transversale genomes at EnsemblFungi were surveyed for RIOLE1 and RIOLE1-LIKE orthologs using BLASTp. The sequences for phylogenetic analyses were aligned using MUSCLE implemented in MEGA 7, and the alignments used to create a maximum-likelihood tree with the WAG +F nucleotide substitution model. Gamma distributed rates with invariant sites $(G+\mathrm{l})$ and 1000 bootstrap iterations were performed [26].

\section{Expression of RIOLE1 and RIOLE1-like in yeast}

The cDNAs of RIOLE1 and RIOLE1-LIKE were amplified from $R$. irregularis RNA isolated from colonized Lotus japonicus roots by RT-PCR (for oligonucleotides, see Supplementary Table S1). The cDNAs were ligated into the expression vector pDR196 using the restriction enzymes Smal and Xhol [27]. The constructs were transferred into Saccharomyces cerevisiae BY4741 (wild type, WT) and the $\Delta$ ole1 mutant (accession Y40963) obtained from EUROSCARF, and transformed cells selected on minimal medium lacking uracil. The growth of $\Delta$ ole 1 was supported by addition of $1 \mathrm{mM}$ oleic acid.

For complementation experiments, single colonies of $\Delta$ ole 1 cells containing different constructs were used to inoculate $20 \mathrm{~mL}$ cultures of minimal medium with or without $1 \mathrm{mM}$ oleic acid $/ 1 \%(\mathrm{v} / \mathrm{v})$ Triton-X 100 , and cells were grown at $33^{\circ} \mathrm{C}$. Alternatively, the cells were spotted in a serial dilution on solid medium and grown at $28^{\circ} \mathrm{C}$ for five days.

Fatty acid feeding experiments were performed with whole $S$. cerevisiae cells. To this end, minimal medium lacking uracil was inoculated with single colonies from plates. Cells were supplemented with $1 \%(\mathrm{v} / \mathrm{v})$ Triton $\mathrm{X}-100$ and $1 \mathrm{mM}$ of $15: 0$ or ${ }^{13} \mathrm{C}_{4}-16: 0$ fatty acid, and grown for 2 days at $28^{\circ} \mathrm{C}$.

\section{Expression of RIOLE1 and RiOLE1-like in plants}

The cDNAs for RIOLE1 and RIOLE1-LIKE were amplified by PCR for expression in Nicotiana benthamiana (for oligonucleotides, see Supplementary Table S1). RiOLE1 was cloned into 
the vector p917RFPUBQExpr (Nicole Gaude, MPI Potsdam-Golm) using BamHI, HindIII, and RiOLE1-LIKE was ligated into the vector pBin35S-DsRed using Mlul, Xhol [28]. The constructs were transferred into Agrobacterium tumefaciens GV3101-pMP90 and used for transient transformation of $N$. benthamiana leaves [29]. Plants with infiltrated leaves were grown at $25^{\circ} \mathrm{C}, 60 \%$ humidity and light intensity of $250 \mathrm{mmol} \mathrm{s}^{-1} \mathrm{~m}^{-2}$ for 4 to 11 days and expression of the DsRed marker was evaluated with a fluorescent lamp (NightSea, Bedford, USA).

For expression in Camelina sativa, RIOLE1 and RIOLE1-LIKE cDNAs were amplified by PCR (for oligonucleotides, see Supplementary Table S1) and cloned into pBinGlyBar1 (Edgar Cahoon, University of Nebraska-Lincoln) using EcoRI, Xhol and transferred into $A$. tumefaciens GV3101. Camelina sativa accession CAM139 (ACCID 243618; IPK Gatersleben, Germany) [30], and a high-palmitate line expressing CpuFatB1 [31] were transformed via vacuum infiltration [32]. T1 plants were germinated and screened by spraying the plants at 5 and 12 days post germination with $0.3 \%(\mathrm{v} / \mathrm{v})$ BASTA (Bayer CropScience) containing $500 \mu \mathrm{L} \mathrm{L}^{-1}$ Silwet L-77. Seeds from resistant plants were harvested for single-seed fatty acid analysis.

\section{Lipid extraction and fatty acid analysis}

Lipids were extracted from yeast cultures and $N$. benthamiana leaves. Yeast cultures were centrifuged at $4000 \mathrm{~g}$ for $10 \mathrm{~min}$ and the pellet resuspended in $4 \mathrm{~mL}$ water and boiled for 5 $\min$. Lipids were extracted with three volumes of chloroform/methanol $(2: 1, v / v)$ after centrifugation at $5 \mathrm{~min}$ for $2000 \mathrm{~g}$ and re-extracted two times with two volumes of chloroform each. Transformed $N$. benthamiana leaf areas were dissected and frozen in liquid nitrogen. Leaves were homogenized in a mortar under liquid nitrogen and the leaf powder was used for lipid extraction with chloroform/methanol/formic acid (1:1:0.1, v/v) and $1 \mathrm{M} \mathrm{KCl} / 0.2 \mathrm{M}$ $\mathrm{H}_{3} \mathrm{PO}_{4}$. The solvent of the lipid extracts were evaporated under $\mathrm{N}_{2}$ gas and the lipids separated by solid-phase extraction or directly used for synthesis of fatty acid methyl esters.

For solid phase extraction, lipids were dissolved in $1 \mathrm{~mL}$ chloroform and loaded onto silica columns (1 mL bed volume; Phenomenex, Torrance, CA, USA). Non polar lipids were eluted with chloroform, galactolipids with acetone/isopropanol 1:1 ( $/ \mathrm{v})$ and phospholipids with methanol. The solvents were evaporated with $\mathrm{N}_{2}$ gas.

Fatty acid methyl esters were synthesized from dried total lipid extracts, solid phase extraction-fractions, or single seeds of Camelina by incubation with $1 \mathrm{~N}$ methanolic $\mathrm{HCl}$ at $80^{\circ} \mathrm{C}$ for $30 \mathrm{~min}$ [33]. Methyl esters were extracted with $\mathrm{n}$-hexane and $0.9 \%(\mathrm{w} / \mathrm{v}) \mathrm{NaCl}$. Camelina seeds were homogenized prior to incubation with methanolic $\mathrm{HCl}$. Fatty acid methyl esters from $R$. irreglaris-colonized $L$. japonicus roots or $R$. irregularis extraradical mycelium (ERM) were prepared as previously described [7]. Fatty acid methyl esters were 
analyzed by gas chromatography with flame ionization detector (Agilent 7890A Plus GC; Agilent, Santa Clara, CA, USA) [4] or by gas chromatography-mass spectrometry (6975C inertXL MSD with Triple-Axis Detector with 7890A GC, Agilent) with an HP 5-MS column (Agilent J\&W, 30 m, 0.25 mm diameter, $0.25 \mu \mathrm{m}$ film). Pentadecanoic acid (15:0) was used as internal standard.

The double bond positions were investigated after conversion of monounsaturated fatty acid methyl esters with dimethyldisulfide (DMDS) into bis(methylthio)-derivatives [34]. Dimethyldisulfide derivatives were analyzed by GC-MS.

\section{Measurement of acyl-CoAs}

Acyl-CoAs were extracted from homogenized leaf material of $N$. benthamiana $(20 \mathrm{mg})$ as described $[35,36]$. For measurement in yeast, the cell pellet of a $2 \mathrm{~mL}$ culture was resuspended in $200 \mu \mathrm{l}$ of the extraction buffer ( $1 \mathrm{~mL}$ isopropanol, $1 \mathrm{~mL} 50 \mathrm{mM} \mathrm{KH}_{2} \mathrm{PO}_{4}, \mathrm{pH}$ 7.2, $25 \mu \mathrm{L}$ acetic acid, $40 \mu \mathrm{L} 50 \mathrm{mg} \mathrm{mL}^{-1}$ fatty acid free bovine serum albumine) and homogenized in the Precellys homogenizer with glass beads. Extracted acyl-CoAs were dissolved in solvent $\mathrm{B}\left(\mathrm{H}_{2} \mathrm{O}\right.$ /acetonitrile; 90:10; v/v; containing $\left.15 \mathrm{mM} \mathrm{NH}_{4} \mathrm{OH}\right)$ and separated on an RP8 column (Knauer Eurospher II, $150 \mathrm{~mm}, 3 \mathrm{~mm}$ ) at a flow rate of $0.5 \mathrm{~mL} \mathrm{~min}^{-1}$ with the following gradient: $0 \mathrm{~min}, 100 \%$ solvent $\mathrm{B} ; 5 \mathrm{~min}, 25 \%$ solvent $\mathrm{A}$ (acetonitrile containing $15 \mathrm{mM} \mathrm{NH}_{4} \mathrm{OH}$ )/75\% solvent $B ; 11-13 \mathrm{~min}, 100 \%$ solvent $A ; 15-18 \mathrm{~min}, 100 \%$ solvent $C$ $\left(\mathrm{H}_{2} \mathrm{O}\right.$ /acetontrile/formic acid, 30:70:0.1, v/v); 20-30 min, 100\% solvent B. Eluted acyl-CoAs were quantified by MS/MS with electrospray ionization on an Agilent 6530 Q-TOF mass spectrometer. Acyl-CoAs were ionized in the positive mode and quantified using the neutral loss of 506.9960 (characteristic for adenosine-3'-phosphate-5'-diphosphate) using 17:0-CoA as internal standard.

\section{Results}

\section{R. irregularis contains two genes with sequence similarity to the S. cerevisiae acyl- CoA desaturase OLE1}

The genome of $R$. irregularis harbors seven open reading frames with sequence similarity to desaturases from Mortierella alpina and Saccharomyces cerevisiae. These genes can be divided into three clades based on amino acid sequence relationship (Figure Supplementary S1). Clade I contains sequences from $M$. alpina with specificity for $\Delta 5$ and $\Delta 6$ desaturation [37] and three $R$. irregularis genes. Clade II contains one $R$. irregularis sequence and two $M$. alpina desaturases specific for $\Delta 12$ and $\omega 3$. The M. alpina and S. cerevisiae OLE1 $\Delta 9$ 
desaturases belong to Clade III and show highest similarity with R. irregularis RIR 1928200 (designated RiOLE1), and the second most similar sequence is RIR 2584800 (RiOLE1LIKE).

Expression of the two genes was recorded in Daucus carota roots growing in tissue culture which were infected with $R$. irregularis (+ myc, intraradical mycelium, IRM) and extraradical mycelium (ERM). Semiquantitative RT-PCR with total RNA revealed that expression of RIOLE1 and RIOLE1-LIKE is similar in IRM and ERM, even though RIOLE1LIKE shows stronger overall expression (Supplementary Figure S2A). Therefore, expression of RIOLE1 or RIOLE1-LIKE is not upregulated in the fungus during AM colonization, but the two genes are constitutively expressed.

To study the biochemical function of $R$. irregularis RiOLE1 and RiOLE1-LIKE, the two cDNAs were transferred into the fatty acid-auxotroph yeast $\Delta$ ole1 mutant. This yeast mutant is deficient in the 18:0-CoA $\Delta 9$ desaturase and therefore can only grow after supplementation of unsaturated fatty acids such as oleic acid $\left(18: 1^{\Delta 9 c i s}\right)$ to the medium. Introduction of RiOLE1 or RiOLE1-LIKE both resulted in complementation of the growth deficiency of $\Delta$ ole 1 (Figure $1 \mathrm{~A}, \mathrm{~B}$ ). The yeast $\Delta$ ole 1 mutant was used to examine the fatty acid desaturation products after heterologous expression of RiOLE1 and RiOLE1-LIKE by GC (Figure 1C). Expression of RiOLE1-LIKE led to the accumulation of the mycorrhiza

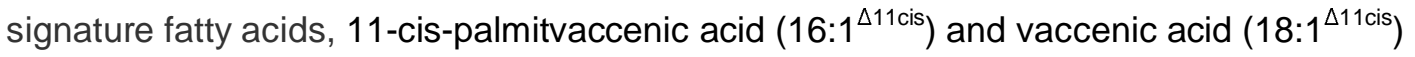
(Figure 1C, Supplementary Figure S2A). On the other hand, expression of RiOLE1 resulted in a strong increase in oleic acid $\left(18: 1^{\Delta 9 c i s}\right)$ content. Expression of the two desaturases in $\triangle$ ole 1 led to a slight decrease in palmitoleic acid $\left(16: 1^{\Delta 9 c i s}\right)$, and RiOLE1 expression slightly affected the myristic acid (14:0) content. However, no desaturation product of 14:0 (14:1) was detected in any yeast strain.

RIOLE1 and RIOLE1-LIKE gene expression in the different yeast cultures was determined by semiquantitative RT-PCR (Figure 1D). RiOLE1 and RiOLE1-LIKE were expressed to the same extents in the recombinant yeast cultures, indicating that the differences in fatty acid desaturation are due to different activities or substrate preferences of the enzymes.

\section{Determination of double bond position of mycorrhiza-signature fatty acids}

The double bond position of unsaturated fatty acids can be determined after covalent modification of double bonds with dimethyldisulfide followed by GC-MS analysis, giving rise to peaks with specific retention times and fragmentation patterns. Therefore, total lipids isolated from the different yeast $\Delta$ ole 1 strains were converted into methyl esters and derivatized with dimethyldisulfide (Figure 2). Four monunsaturated fatty acids were present in the total fatty acid extracts (Supplementary Figure S3). Their fragmentation patterns allowed 
the identification of the double bonds at $\Delta 9$ of palmitoleic acid $\left(16: 1^{\Delta 9 i s}\right)$ and oleic acid $\left(18: 1^{\Delta 9 \mathrm{cis}}\right)$ (Figure $\left.2 \mathrm{~A}, 2 \mathrm{C}\right)$ and $\Delta 11$ for palmitvaccenic acid $\left(16: 1^{\Delta 11 \mathrm{cis}}\right)$ and vaccenic acid $\left(18: 1^{\Delta 11 \text { cis }}\right.$ ) (Figure 2B, 2D). While palmitoleic acid and oleic acid accumulated in RiOLE1 expressing cells, palmitvaccenic acid and vaccenic acid were abundant in RiOLE1-LIKE cells (Supplementary Figure S3).

\section{Heterologous expression of RiOLE1 and RIOLE1-LIKE in transgenic plants}

To characterize the two $R$. irregularis desaturases in a non-fungal background, Agrobacterium harboring vectors with the RiOLE1 and RiOLE1-LIKE cDNAs were infiltrated into Nicotiana benthamiana leaves for transient expression (Supplementary Figure S4). Expression of RiOLE1 resulted in an increase in oleic acid in non polar lipids, galactolopids and phospholipids, accompanied by increased 18:2 content in non polar lipids and phospholipids (Supplementary Figure S4A). RiOLE1-LIKE expression in N. benthamiana leaves led to the accumulation of 16:1 ${ }^{\Delta 11 \text { cis }}$, particularly in neutral lipids and phospholipids but not galactolipids (Supplementary Figure S4B). These results are in agreement with the data obtained from heterologous expression in yeast and demonstrate that RiOLE1 and RiOLE1LIKE encode a $\Delta 9$ and $\Delta 11$ desaturase, respectively.

It is known that unusual fatty acids such as $16: 1^{\Delta 11 \text { cis }}$ are excluded from plant membrane lipids, but they can accumulate in the seed oils of many plants [38]. We therefore expressed RiOLE1-LIKE using a seed-specific promoter in Camelina to study the fatty acid composition of the oil in mature seeds. Fatty acid measurement showed that $16: 1^{\Delta 11 \text { cis }}$ accumulated to $0.03-0.08$ mol\% in single transgenic RIOLE1-LIKE expressing Camelina seeds (Supplementary Table S2), while it was undetectable in WT seeds. In addition, the content of $20: 1^{\Delta 11}$ increased from $12.7 \mathrm{~mol} \%$ to 17.5 - 20.5 mol\% when RiOLE1-LIKE was expressed. The very low amount of 16:1 ${ }^{\Delta 11 c i s}$ in transgenic Camelina seeds might be due to the low availability of the substrate, 16:0, because Camelina seeds mostly accumulate C18 fatty acids. We therefore introduced the RIOLE1-LIKE construct into a high 16:0-containing Camelina line [31]. This line carries an overexpression construct for the acyl-ACP thioesterase CpuFatB1 from Cuphea pulcherrima resulting in the termination of fatty acid synthesis at C16, and in the accumulation of 16:0 in the seed oil from $\sim 11 \%$ to $42 \%$ (Supplementary Table S2). Expression of RiOLE1-LIKE in transgenic CpuFatB1 seeds resulted in the increase in palmitvaccenic acid content to 0.24 - $0.82 \mathrm{~mol} \%$ (Supplementary Table S2). Likewise, the content of 20:1 ${ }^{\Delta 11}$ was slightly increased, albeit total amounts were lower compared with CAM139 transformed seeds. Taken together, RiOLE1-LIKE expression in the seeds of Camelina resulted in the accumulation of 16:1 ${ }^{\Delta 11 c i s}$, albeit with low amounts, and the amount was increased but still $<1 \mathrm{~mol} \%$ in a high pamitic acid Camelina line. 


\section{Addition of exogenous fatty acids to yeast}

To examine fatty acid substrate specificity of RIOLE1 and RIOLE1-LIKE in more detail, fatty acids were added to growing yeast cultures. We first added a stable isotope labeled 16:0 fatty acid $\left({ }^{13} \mathrm{C}_{4}-16: 0\right)$ to follow the incorporation of label into the different desaturation and elongation products. When ${ }^{13} \mathrm{C}_{4}-16: 0$ was supplied to the yeast cells, the ${ }^{13} \mathrm{C}_{4}$-label accumulated in all fatty acids in WT, but was strongly reduced in 16:1 ${ }^{\Delta 9 c i s}$ and 18:1 ${ }^{\Delta 9 c i s}$ in the $\triangle$ ole1 mutant where 18:0 accumulated instead (Figure 3A). Upon expression of RiOLE1 and RiOLE1-LIKE in $\triangle$ ole $1,{ }^{13} \mathrm{C}_{4}$-label accumulation in 16:1 ${ }^{\Delta 9 c i s}$ was even further decreased. In addition, oleic acid became abundantly labeled when RIOLE1 was expressed in $\triangle$ ole1, while expression of RIOLE1-LIKE in $\triangle$ ole 1 led to the most abundant accumulation of ${ }^{13} \mathrm{C}_{4}$-label in $16: 1^{\Delta 11 \text { cis }}(54.44 \mathrm{~mol} \%)$ and none in $18: 1^{\Delta 9 \text { cis }}$.

Next, we added the odd-chain fatty acid pentadecanoic acid (15:0) to $\Delta$ ole1 cells expressing RIOLE1 or RIOLE-LIKE. 15:0 was taken up by the cells and elongated to margaric acid (17:0), and both 15:0 and 17:0 were desaturated to $15: 1^{9 \text { cis }}$ and 17:1 ${ }^{9 \text { cis }}$, respectively, in $\triangle$ ole1 cells expressing RiOLE1 (Figure 3B). When RiOLE1-LIKE was expressed in $\triangle$ ole 1, 15:0 and 17:0 were converted into two new peaks which were tentatively identified as $15: 1^{\Delta 11 \text { cis }}$ and $17: 1^{\Delta 11 \text { cis }}$ based on their retention time.

\section{Acyl-CoA composition in yeast cells and plants expressing $\boldsymbol{R}$. irregularis desaturases}

Acyl-CoAs are important intermediates of fatty acid metabolism, and they are the substrate for the OLE1 desaturase from S. cerevisiae. Acyl-CoAs were quantified in yeast cells and $N$. benthamiana leaves expressing RiOLE1 or RIOLE1-LIKE (Figure 4) by LC-MS/MS. In this method, acyl-CoAs containing different numbers of carbon atoms or double bonds in the acyl chain can be separated and quantified using an internal standard. However, it is not possible to separate isomeric monounsaturated acyl-CoAs containing the double bond at different positions. In yeast $\triangle$ ole1, 16:1-CoA and 18:1-CoA decreased while 16:0-CoA, 18:0-CoA and 20:0-CoA accumulated, compared to WT (Figure 4A). Expression of RiOLE1-LIKE in Dole1 led to a very strong increase in 16:1-CoA (43.6 mol\%) and to a lesser increase in 18:1-CoA (7.6 mol\%) while the amount of 20:0-CoA (2.9 mol\%) was decreased. On the other hand, 18:1-CoA increased most predominantly when RiOLE1 was expressed (26.7 mol\%).

Expression of RiOLE1-LIKE in N. benthamiana leaves led to the accumulation of 16:1-CoA (16.8 mol\%) accompanied with a decrease in 16:0-CoA (41.1 mol\%) that was not detected in control leaves (Figure 4B). Expression of RiOLE1 led to the increase in 18:1-CoA to $5.2 \mathrm{~mol} \%$, which remained low in the control (1.3 mol\%) and RIOLE1-LIKE (2.2 mol\%).

Taken together, these results are in agreement with a substrate/product relationship of 18:0CoA/18:1-CoA and 16:0-CoA/16:1-CoA for RIOLE1 and RiOLE1-LIKE, respectively, suggesting that RIOLE1 and RIOLE-LIKE are acyl-CoA desaturases. 


\section{The OLE1-LIKE genes are conserved in AM Glomeromycotina, but not in non- symbiotic Mucoromycota}

AM fungi of the Glomeromycotina likely evolved from saprotrophic Mucoromycota [39]. To study the evolution of RiOLE1 and RiOLE1-LIKE sequences and their distribution in the different fungal phyla, the two desaturase sequences from $R$. irregularis were used to identify orthologs in other Glomeromycotina as well as non-mycorrhizal Mucoromycota using protein Blast searches. Protein sequences of several fungal species were retrieved and used to assemble a phylogenetic tree (Figure 5). Two major clades were identified, one clade that compromises sequences similar to RiOLE1-LIKE that were present in all five representatives of the Glomeromycotina. These sequences were more similar to each other than to the sequences organized in the second clade representing the sequences highly similar to RiOLE1. Sequences similar to RiOLE1 were found in all six Glomeromycotina species and in the non-symbiotic Mortierellaceae (M. alpina, M. elongata, L. transversale) as well as in the non-symbiotic Mucoromycotina (M. circinelloides, $R$. microsporus). Thus, OLE1-LIKE is conserved in symbiotic Glomales and Diversisporales, but not in non-symbiotic fungi, suggesting that it evolved to fulfill a specific function in AM fungi.

\section{Discussion}

\section{RiOLE1 and RiOLE1-LIKE are front-end desaturases}

Desaturases are classified based on their ability to either recognize the methyl $(\omega)$ or carboxyl $(\Delta)$ end of fatty acids for insertion of the double bond [40]. The double bond position of fatty acids can be identified after derivatization with dimethyldisulfide. Thus, four monounsaturated fatty acids were detected in $\triangle$ ole 1 cells expressing RiOLE1-LIKE, i.e. 16:1 $1^{\Delta 9 \text { cis }}, 16: 1^{\Delta 11 \text { cis }}, 18: 1^{\Delta 9 \text { cis }}, 18: 1^{\Delta 11 \text { cis }}$ (Figure 2, Supplementary Figure S3). The fatty acids 16:1 ${ }^{\Delta 9 \text { cis }}$ and 18:1 ${ }^{\Delta 9 \text { cis }}$ are also present in the $\Delta$ ole 1 control and are therefore derived from residual activity of ScOLE1 rather than from RiOLE1-LIKE. 16:1 ${ }^{\Delta 11 \text { cis }}$ could in principle be derived from front end $(\Delta 11)$ or methyl end $(\omega 5)$ desaturation. However, 18:1 ${ }^{\Delta 11 \text { cis }}$ must be derived from $\Delta 11$ desaturation. This fatty acid cannot be the product of $16: 1^{\Delta 11 c i s}$ elongation by addition of two carbons at the carboxyl end, which would have resulted in 18:1 ${ }^{\Delta 13 c i s}$ production. Similarly, $\omega 5$ desaturation of $18: 0$ by RIOLE1-LIKE would also have resulted in 
the production of 18:1 ${ }^{\Delta 13 c i s}$. Likewise, upon RiOLE1 expression in $\triangle$ ole 1 , only $16: 1^{\Delta 9 c i s}$ and 18:1 $1^{\Delta 9 c i s}$ were produced. While $18: 1^{\Delta 9 c i s}$ could in principle be produced via $\Delta 9$ or $\omega 9$ desaturation, $16: 1^{\Delta 9 \text { cis }}$ is clearly derived from $\Delta 9$ desaturation of $16: 0$, because $\omega 9$ desaturation would result in 16:1 ${ }^{\Delta 7 \text { cis }}$ production, and elongation of a putative $14: 1^{\Delta 7 \text { cis }}$ precursor is not likely as it was not detected.

These conclusions are corroborated by the fatty acid analysis of yeast $\Delta$ ole 1 cultures after 15:0 feeding (Figure 3). In this experiment, $15: 1^{\Delta 9}$ and $17: 1^{\Delta 9}$ were strongly increased after expression of RiOLE1 compared with the control. Expression of RiOLE1-LIKE in $\triangle$ ole1 cells resulted in the accumulation of $15: 1^{\Delta 11}$ and 17:1 $1^{\Delta 11}$ from 15:0. Taken together, these data demonstrate that RIOLE1 and RIOLE1-LIKE are front-end desaturases that count carbon atoms from the carboxyl-terminus for insertion of the double bond at positions $\Delta 9$ or $\Delta 11$, respectively.

\section{RiOLE1 and RiOLE1-LIKE likely are acyl-CoA desaturases with specifies for long chain fatty acids}

RiOLE1 and RiOLE1-LIKE show sequence similarity with the yeast acyl-CoA desaturase OLE1 (Supplementary Figure S1) and can functionally replace OLE1 in the $\triangle$ ole 1 mutant, strongly promoting growth in the absence of exogenous unsaturated fatty acids (Figure 1). In similar approaches, desaturases from rat or Rhodosporidium with sequence similarity to OLE1 were characterized $[41,42]$. Expression of RIOLE1 and RiOLE1-LIKE leads to alteration in acyl-CoA composition in yeast and plants with a clear substrate to product relationship (Figure 4). While RIOLE1 expression resulted in an increase in 18:1-CoA and a decrease in 18:0-CoA, expression of RIOLE1-LIKE caused an increase in 16:1-CoA and a reduction in 16:0-CoA, both compared with $\triangle$ ole1. Therefore, RiOLE1 and RiOLE1-LIKE likely are acyl-CoA desaturases.

Expression of RIOLE1 in plants ( $N$. benthamiana leaves, Camelina seeds) led to a very low production of $16: 1^{\Delta 11 \text { cis }}$. (Supplementary Table S1, Supplementary Figure S4). In plants, most desaturation reactions take place on lipid-bound acyl groups, i.e phosphatidylcholine at the ER, before acyl groups are redistributed to other membrane lipids in the leaves or to triacylglycerol in the seeds. Introduction of heterologous acyl-CoA desaturases into plants oftentimes results in low production of the new unsaturated fatty acid because it has to be channeled between the phosphatidylcholine and CoA thioester pools, and this redistribution is slow [43].

Furthermore, addition of exogenous 15:0 resulted in the accumulation of the respective desaturation products $\left(15: 1^{\Delta 11 \text { cis }}, 17: 1^{\Delta 11 \text { cis }}\right.$ for RiOLE1-LIKE; $15: 1^{\Delta 9 \text { cis }}, 17: 1^{\Delta 9 \text { cis }}$ for RiOLE1; Figure 3B) indicating that the two enzymes are to a certain degree promiscuous in their substrate specificity and accept a range of long-chain (C15-C18) fatty acids. 
Feeding of ${ }^{13} \mathrm{C}_{4}$-labeled 16:0 revealed the accumulation of the ${ }^{13} \mathrm{C}_{4}$-label in all endogenous yeast fatty acids (Figure 4A). Yeast OLE1 is able to desaturate 16:0 and 18:0 [41]. When ${ }^{13} \mathrm{C}_{4}-16: 0$ was offered, ${ }^{13} \mathrm{C}_{4}$-label accumulated in 18:0 (27.0 mol\%) in yeast WT. This was sufficient as substrate for SCOLE1 to produce ${ }^{13} \mathrm{C}_{4}-18: 1^{\Delta 9 c i s}$, even though this product only accumulated to $7.4 \mathrm{~mol} \%$. Using the same conditions, no ${ }^{13} \mathrm{C}_{4}$-label was found in 18:1 $1^{\Delta 11 \text { is }}$ in $\triangle$ ole 1 expressing RIOLE1-LIKE, even though sufficient substrate was available (42.5 mol\% of $\left.{ }^{13} \mathrm{C}_{4}-18: 0\right)$. Therefore, RiOLE1-LIKE has much poorer activity on 18:0 than yeast SCOLE1, and consequently RIOLE1-LIKE has a strong preference for the 16:0 substrate (Figure 1C, 2D). 18:0 desaturation in $R$. irregularis is probably foremost conducted by RiOLE1, in accordance with the accumulation of ${ }^{13} \mathrm{C}_{4}-18: 1^{\Delta 9 c i s}$ (34.4 mol\%) while only miniature amounts of ${ }^{13} \mathrm{C}_{4}-16: 1^{\triangle 9 c i s}$ (2.6 mol\%) were detected upon RiOLE1 expression. Functional differentiation of acyl-CoA desaturases was reported before for mice where four desaturases exist, three act on 16:0-CoA and 18:0-CoA and one is specialized for acyl-CoAs with fatty acids < 16:0 [44].

\section{OLE1-LIKE evolved in AM fungi}

OLE1-LIKE is conserved in the Glomerales $R$. clarus, $R$. irregularis, $R$. diaphanus, $R$. cerebriforme and in $G$. rosea (Diversisporales) but not in the other non-symbiotic, nonmycorhizal Mucoromycota (Figure 5). The Mucoromycota species only contain OLE1 orthologs. A characteristic feature of Glomeromycotina are their large genomes with high numbers of duplicated genes, compared to Mortierellamycotina and Mucorocmycotina [25]. Therefore, the OLE1-LIKE gene could originate from gene duplication of OLE1 and neofunctionalization in Glomeromycotina and might have evolved to fulfill a specific function during the obligate mutualistic AM symbiosis. The expression pattern of RiOLE1-LIKE in IRM

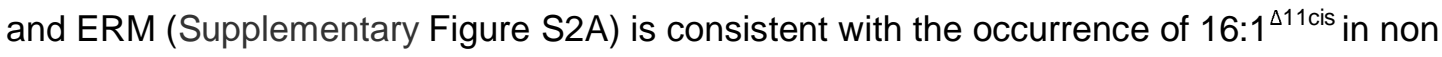
polar storage lipids and membrane-forming phospholipids in IRM and ERM, even though considerably less $16: 1^{\Delta 11 c i s}$ is found in the IRM [13].

\section{Possible functions of $16: 1^{\Delta 11 c i s}$ in AM fungi}

Interestingly, overexpression of the $S$. saccharomyces $\Delta 9$ desaturase (OLE1) or of an insect $\Delta 11$ desaturase, which resulted in the accumulation of $16: 1^{\Delta 9 c i s}$ and $16: 1^{\Delta 11 \text { cis }}$ in transgenic Nicotiana tabacum leaves, respectively, led to the accumulation of lipoxygenase products, in particular cis-3-hexenal [45]. The same effect was observed when the two fatty acids were exogenously applied to $N$. tabacum leaves. The authors concluded that the presence of unusual monounsaturated $\mathrm{C} 16$ fatty acids stimulated the lipoxygenase pathway thereby contributing to enhanced resistance against pathogens. In line with this finding, overexpression of $S$. cerevisiae OLE1 in tomato or in eggplant increased the resistance 
against powdery mildew (Erysiphe polygoni) and Verticillium wilt (Verticillium dahliae) $[46,47]$.

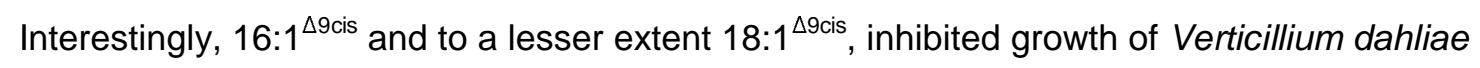
at $\mu \mathrm{M}$ concentrations. Therefore, it is possible that monounsaturated $\mathrm{C} 16$ fatty acids, in particular 16:1 ${ }^{\Delta 11 \text { cis }}$, which accumulates in membrane and storage lipids, protect AM fungal spores and hyphae in the soil against attack by bacteria or other fungi. Furthermore, the unusual 16:1 ${ }^{\Delta 11 \text { cis }}$ fatty acid could be involved in recognition of the AM fungi by the plant host. Membrane lipids of pathogenic fungi are recognized by the plant host as shown by the elicitation of defense responses after application of ergosterol $[48,49] .16: 1^{\Delta 11 \text { cis }}$ possibly fulfills an opposite function during symbiosis, because it might be perceived by the host as a symbiotic signature to avoid the host's immune response.

On the other hand, certain fatty acid combinations of membrane lipids are elicitors in plant-pathogen interactions, as shown by $18: 2,18: 1$ and 16:0-containing phosphatidylcholine and phosphatidylethalonamine from female Sogatella furcifera eggs [50]. Acyl editing in IRM of $R$. irregularis suggests that $16: 1^{\Delta 11 \text { cis }}$ could also be perceived by the host as potential pathogenic elicitor as $R$. irregularis alters its phospholipid fatty acid composition and suppresses di-16:1 and 24:1 when growing intraradically [4]. Therefore, 16:1 ${ }^{\Delta 11 \text { cis }}$ biosynthesis could have been evolved in Glomeromycota for survival in the hostile soil environment during asymbiotic growth and it might be beneficial during host perception and symbiotic growth.

\section{Abbreviations}

ACP, acyl carrier protein; AM, arbuscular mycorrhiza; CoA, coenzyme A; ERM, extraradical mycelium; IRM, intraradical mycelium; WT, wild type.

Fatty acids are abbreviated as $X: Y$, where $X$ depicts the number of carbon atoms, and $Y$ the number of double bonds in the acyl chain.

\section{Author Contribution}

M.B., E.B.C. and P.D. conceived the project. M.B. and P.D. designed the research. M.B. performed the experiments. M.B. and P.D. analyzed data and wrote the article.

\section{Funding}

This research was supported by the Deutsche Forschungsgemeinschaft (grant Do520/15-1 and Graduiertenkolleg GRK2064) to P.D.

\section{Competing Interests}

The Authors declare that there are no competing interests associated with the manuscript. 


\section{Figure legends}

Figure 1. Complementation of yeast $\Delta$ ole1 mutant growth by heterologous expression of Rhizophagus desaturases.

RiOLE1 or RiOLE1-LIKE cDNAs were expressed in S. cerevisiae WT and the Dole1 mutant cells. Cells were grown in minimal medium with or without supplementation of oleic acid $\left(18: 1^{\Delta 9 c i s}\right)$. (A) Spotting growth assay of yeast cultures. Cells of 10 fold dilutions were pipetted onto solid medium and grown at $28^{\circ} \mathrm{C}$ for five days. (B) Liquid cultures were inoculated from single colonies and grown at $33^{\circ} \mathrm{C}$ for up to three days, and the $\mathrm{OD}_{600}$ was recorded. (C) Fatty acid composition of yeast WT and $\triangle$ ole 1 cells expressing RIOLE1 or RIOLE1-LIKE. Total lipids were extracted from the harvested cells and used for synthesis of fatty acid methyl ester which were quantified by GC. Bars show means \pm SD. Letters indicate significant differences between treatments (ANOVA; posthoc Tukey; $p \leq 0.05 ; n=3$ ). (D) Expression of RiOLE1 or RiOLE1-LIKE in yeast WT and $\triangle$ ole1. RNA was isolated from WT or $\Delta$ ole1 cells transformed with empty vector (EV), RiOLE1 or RiOLE1-LIKE constructs. Transcript abundance was measured by RT-PCR with primers for RiOLE1, RiOLE1-LIKE or ACTIN. PCR products were separated on agarose gels and stained with ethidium bromide.

Figure 2. Determination of double bond position monounsaturated fatty acids isolated from RIOLE1 or RIOLE1-LIKE expressing yeast.

Lipids were isolated from yeast $\triangle$ ole1 mutant cells expressing RiOLE1-LIKE and fatty acid converted into methyl esters. Double bonds were derivatized with dimethylsidulfide and the products analyzed by GC-MS (for chromatograms, see Supplementary Figure S2). Mass spectra are and structures are shown for $\mathbf{A}, 16: 1^{\Delta 9 \text { cis }} ; \mathbf{B}, 16: 1^{\Delta 11 \text { cis }} ; \mathbf{C}, 18: 1^{\Delta 9 \mathrm{cis}} ; \mathbf{D}, 18: 1^{\Delta 11 \text { cis }}$. $F_{a}$, fragment $a ; F_{b}$, fragment $b$.

Figure 3. Desaturation of exogenously supplied fatty acids in yeast cells expressing Rhizophagus desaturases.

S. cerevisae cells (WT, $\triangle$ ole1) expressing RIOLE1 or RIOLE1-LIKE were grown for three days at $28^{\circ} \mathrm{C}$ in minimal medium supplemented with (A) $1 \mathrm{mM}{ }^{13} \mathrm{C}_{4}-16: 0$ or (B) $1 \mathrm{mM} \mathrm{15:0.}$ Lipids were extracted from cell pellets and used for fatty acid analysis of methyl esters by GC-MS. (A) The amount of overexcess ${ }^{13} \mathrm{C}_{4}$ accumulation (mol\%) was quantified in the different fatty acid methyl esters. Letters indicate significant differences among treatments (ANOVA; posthoc Tukey, $p \leq 0.05, n=3$ ). Bars represent means \pm SD. n.d., not detected; $E V$, empty vector. (B) GC Chromatograms showing methyl esters of yeast lipids after 15:0 feeding. 
Figure 4. Acyl-CoA composition in transformed yeast cells and $N$. benthamiana leaves expressing Rhiozphagus desaturases.

Acyl-CoAs were measured by LC-MS/MS. (A) Acyl-CoAs in yeast cells (WT, $\Delta$ ole1) expressing empty vector (EV) control, RiOLE1 or RiOLE1-LIKE. (B) Acyl-CoAs in N. benthamiana leaves transiently expressing EV control, RiOLE1 or RiOLE1-LIKE. Letters indicate significant differences among treatments (ANOVA; posthoc Tukey; $p \leq 0.05$. Bars represent means $\pm \mathrm{SD}(\mathrm{n}=3)$. Sc, Saccharomyces cerevisiae; Nb, Nicothiana benthamiana; n.d., not detected.

Figure 5. Phylogenetic tree of OLE1 and OLE1-LIKE sequences from Mucoromycota. OLE1 and OLE1-LIKE from $R$. irregularis were used to identify orthologs in species of other Glomeromycotina, Mortierellamycotina and Mucoromycotina [25]. Amino acid sequences were aligned using MUSCLE with MEGA 7 and a maximum-likelihood tree constructed with 1000 bootstrap iterations as depicted on the nodes. 


\section{References}

1 MacLean, A. M., Bravo, A. and Harrison, M. J. (2017) Plant signaling and metabolic pathways enabling arbuscular mycorrhizal symbiosis. Plant Cell 29, 2319-2335 https://doi.org/10.1105/tpc.17.00555

2 Luginbuehl, L. H. and Oldroyd, G. E. D. (2017) Understanding the arbuscule the heart of endomycorrhizal symbioses in plants. Curr. Biol. 27, R952-R963 https://doi.org/10.1016/j.cub.2017.06.042

3 Luginbuehl, L. H., Menard, G. N., Kurup, S., van Erp, H., Radhakrishnan, G. V., Breakspear, A., Oldroyd, G. E. D. and Eastmond, P. J. (2017) Fatty acids in arbuscular mycorrhizal fungi are synthesized by the host plant. Science 356, 1175-1178 https://doi.org/10.1126/science.aan0081

4 Wewer, V., Brands, M. and Dörmann, P. (2014) Fatty acid synthesis and lipid metabolism in the obligate biotrophic fungus Rhizophagus irregularis during mycorrhization of Lotus japonicus. Plant J. 79, 398-412 https://doi.org/10.1111/tpj.12566

5 Jiang, Y., Wang, W., Xie, Q., Liu, N., Liu, L., Wang, D., Zhang, X., Yang, C., Chen, X. and Tang, D. et al. (2017) Plants transfer lipids to sustain colonization by mutualistic mycorrhizal and parasitic fungi. Science 356, 1172-1175 https://doi.org/10.1126/science.aam9970

6 Keymer, A., Pimprikar, P., Wewer, V., Huber, C., Brands, M., Bucerius, S. L., Delaux, P.-M., Klingl, V., Röpenack-Lahaye, E. v. and Wang, T. L. et al. (2017) Lipid transfer from plants to arbuscular mycorrhiza fungi. eLife 6, e29107 https://doi.org/10.7554/eLife.29107

7 Brands, M., Wewer, V., Keymer, A., Gutjahr, C. and Dörmann, P. (2018) The Lotus japonicus acylacyl carrier protein thioesterase FatM is required for mycorrhiza formation and lipid accumulation of Rhizophagus irregularis. Plant J. 95, 219-232 https://doi.org/10.1111/tpj.13943

8 Bravo, A., Brands, M., Wewer, V., Dörmann, P. and Harrison, M. J. (2017) Arbuscular mycorrhizaspecific enzymes FatM and RAM2 fine-tune lipid biosynthesis to promote development of arbuscular mycorrhiza. New Phytol. 214, 1631-1645 https://doi.org/10.1111/nph.14533

9 Kameoka, H., Tsutsui, I., Saito, K., Kikuchi, Y., Handa, Y., Ezawa, T., Hayashi, H., Kawaguchi, M. and Akiyama, K. (2019) Stimulation of asymbiotic sporulation in arbuscular mycorrhizal fungi by fatty acids. Nat. Microbiol. 4, 1654-1660 https://doi.org/10.1038/s41564-019-0485-7

10 Sugiura, Y., Akiyama, R., Tanaka, S., Yano, K., Kameoka, H., Kawaguchi, M., Akiyama, K. and Saito, K. (2019) Myristate as a carbon and energy source for the asymbiotic growth of the arbuscular mycorrhizal fungus Rhizophagus irregularis. bioRxiv, doi:10.1101/731489

11 Trepanier, M., Becard, G., Moutoglis, P., Willemot, C., Gagne, S., Avis, T. J. and Rioux, J.-A. (2005) Dependence of arbuscular-mycorrhizal fungi on their plant host for palmitic acid synthesis. Appl. Environm. Microbiol. 71, 5341-5347 https://doi.org/10.1128/AEM.71.9.5341-5347.2005

12 Graham, J. H., Hodge, N. C. and Morton, J. B. (1995) Fatty acid methyl ester profiles for characterization of glomalean fungi and their endomycorrhizae. Appl. Environm. Microbiol. 61, 58-64

13 Olsson, P. A. and Johansen, A. (2000) Lipid and fatty acid composition of hyphae and spores of arbuscular mycorrhizal fungi at different growth stages. Mycol. Res. 104, 429-434 https://doi.org/10.1017/S0953756299001410

14 Reich, M., Göbel, C., Kohler, A., Buée, M., Martin, F., Feussner, I. and Polle, A. (2009) Fatty acid metabolism in the ectomycorrhizal fungus Laccaria bicolor. New Phytol. 182, 950-964 https://doi.org/10.1111/j.1469-8137.2009.02819.x 
15 Campos, A. N. d. R., Costa, M. D., Tótola, M. R. and Borges, A. C. (2008) Total lipid and fatty acid accumulation during basidiospore formation in the ectomycorrhizal fungus Pisolithus sp. Rev. Bras. Ciênc. Solo 32, 1531-1540 https://doi.org/10.1590/S0100-06832008000400017

16 Walker, R. W. (1969) Cis-11-hexadecenoic acid from Cytophaga hutchinsonii lipids. Lipids 4, 15$18 \mathrm{https}: / /$ doi.org/10.1007/BF02531788

17 Hofmann, K. and Tausig, F. (1955) The chemical nature of the fatty acids of a group C Streptococcus species. J. Biol. Chem. 213, 415-423

18 Bjostad, L. B. and Roelofs, W. L. (1983) Sex pheromone biosynthesis in Trichoplusia ni: Key steps involve delta-11 desaturation and chain-shortening. Science 220, 1387-1389 https://doi.org/10.1126/science.220.4604.1387

19 Ding, B.-J., Hofvander, P., Wang, H.-L., Durrett, T. P., Stymne, S. and Löfstedt, C. (2014) A plant factory for moth pheromone production. Nat. Commun. 5, 3353 https://doi.org/10.1038/ncomms4353

20 Dalpé, Y., Trépanier, M., Sahraoui, A. L.-H., Fontaine, J. and Sancholle, M. (2012) 8 Lipids of Mycorrhizas. In Fungal Associations (Hock, B., ed.), pp. 137-16910.1007/978-3-642-30826-0_8 https://doi.org/10.1007/978-3-642-30826-0_8

21 Nordby, H. E., Nemec, S. and Nagy, S. (1981) Fatty acids and sterols associated with citrus root mycorrhizae. J. Agricult. Food Chem. 29, 396-401 https://doi.org/10.1021/jf00104a043

22 Olsson, P. A., Bååth, E., Jakobsen, I. and Söderström, B. (1995) The use of phospholipid and neutral lipid fatty acids to estimate biomass of arbuscular mycorrhizal fungi in soil. Mycol. Res. 99, 623-629 https://doi.org/10.1016/S0953-7562(09)80723-5

23 Schliemann, W., Ammer, C. and Strack, D. (2008) Metabolite profiling of mycorrhizal roots of Medicago truncatula. Phytochemistry 69, 112-146 https://doi.org/10.1016/j.phytochem.2007.06.032

24 Stumpe, M., Carsjens, J.-G., Stenzel, I., Gobel, C., Lang, I., Pawlowski, K., Hause, B. and Feussner, I. (2005) Lipid metabolism in arbuscular mycorrhizal roots of Medicago truncatula. Phytochemistry 66, 781-791 https://doi.org/10.1016/j.phytochem.2005.01.020

25 Morin, E., Miyauchi, S., San Clemente, H., Chen, E. C. H., Pelin, A., La Providencia, I. de, Ndikumana, S., Beaudet, D., Hainaut, M. and Drula, E. et al. (2019) Comparative genomics of Rhizophagus irregularis, $R$. cerebriforme, $R$. diaphanus and Gigaspora rosea highlights specific genetic features in Glomeromycotina. New Phytol. 222, 1584-1598 https://doi.org/10.1111/nph.15687

26 Kumar, S., Stecher, G., Li, M., Knyaz, C. and Tamura, K. (2018) MEGA X: Molecular Evolutionary Genetics Analysis across Computing Platforms. Mol. Biol. Evolut. 35, 1547-1549 https://doi.org/10.1093/molbev/msy096

27 Rentsch, D., Laloi, M., Rouhara, I., Schmelzer, E., Delrot, S. and Frommer, W. B. (1995) NTR1 encodes a high affinity oligopeptide transporter in Arabidopsis. FEBS Lett. 370, 264-268 https://doi.org/10.1016/0014-5793(95)00853-2

28 Patwari, P., Salewski, V., Gutbrod, K., Kreszies, T., Dresen-Scholz, B., Peisker, H., Steiner, U., Meyer, A. J., Schreiber, L. and Dörmann, P. (2019) Surface wax esters contribute to drought tolerance in Arabidopsis. Plant J., 1-18 https://doi.org/10.1111/tpj.14269

29 Wood, C. C., Petrie, J. R., Shrestha, P., Mansour, M. P., Nichols, P. D., Green, A. G. and Singh, S. P. (2009) A leaf-based assay using interchangeable design principles to rapidly assemble multistep recombinant pathways. Plant Biotechnol. J. 7, 914-924 https://doi.org/10.1111/j.1467-7652.2009.00453.x

30 Marmon, S., Sturtevant, D., Herrfurth, C., Chapman, K., Stymne, S. and Feussner, I. (2017) Two acyltransferases contribute differently to Inolenic acid levels in seed oil. Plant Physiol. 173, 2081-2095 https://doi.org/10.1104/pp.16.01865 
31 Kim, H. J., Silva, J. E., Vu, H. S., Mockaitis, K., Nam, J.-W. and Cahoon, E. B. (2015) Toward production of jet fuel functionality in oilseeds: identification of FatB acyl-acyl carrier protein thioesterases and evaluation of combinatorial expression strategies in Camelina seeds. J. Exp. Bot. 66, 4251-4265 https://doi.org/10.1093/jxb/erv225

32 Lu, C. and Kang, J. (2008) Generation of transgenic plants of a potential oilseed crop Camelina sativa by Agrobacterium-mediated transformation. Plant Cell Rep. 27, 273-278 https://doi.org/10.1007/s00299-007-0454-0

33 Browse, J., McCourt, P. J. and Somerville, C. R. (1986) Fatty acid composition of leaf lipids determined after combined digestion and fatty acid methyl ester formation from fresh tissue. Anal. Biochem. 152, 141-145 https://doi.org/10.1016/0003-2697(86)90132-6

34 Francis, G. W. (1981) Alkylthiolation for the determination of double-bond position in unsaturated fatty acid esters. Chem. Phys. Lipids 29, 369-374 https://doi.org/10.1016/00093084(81)90070-0

35 Larson, T. R. and Graham, I. A. (2001) A novel technique for the sensitive quantification of acyl CoA esters from plant tissues. Plant J. 25, 115-125 https://doi.org/10.1111/j.1365313X.2001.00929.x

36 Domergue, F., Abbadi, A., Zähringer, U., Moreau, H. and Heinz, E. (2005) In vivo characterization of the first acyl-COA $\triangle 6$-desaturase from a member of the plant kingdom, the microalga Ostreococcus tauri. Biochem. J. 389, 483-490 https://doi.org/10.1042/BJ20050111

37 Kikukawa, H., Sakuradani, E., Ando, A., Shimizu, S. and Ogawa, J. (2018) Arachidonic acid production by the oleaginous fungus Mortierella alpina 1S-4. A review. J. Adv. Res. 11, 15-22 https://doi.org/10.1016/j.jare.2018.02.003

38 Badami, R. and Patil, K. (1980) Structure and occurrence of unusual fatty acids in minor seed oils. Prog. Lipid Res. 19, 119-153 https://doi.org/10.1016/0163-7827(80)90002-8

39 Spatafora, J. W., Chang, Y., Benny, G. L., Lazarus, K., Smith, M. E., Berbee, M. L., Bonito, G., Corradi, N., Grigoriev, I. and Gryganskyi, A. et al. (2016) A phylum-level phylogenetic classification of zygomycete fungi based on genome-scale data. Mycol. 108, 1028-1046 https://doi.org/10.3852/16-042

40 Meesapyodsuk, D. and Qiu, X. (2012) The front-end desaturase: Structure, function, evolution and biotechnological use. Lipids 47, 227-237 https://doi.org/10.1007/s11745-011-3617-2

41 Stukey, J. E., McDonough, V. M. and Martin, C. E. (1990) The OLE1 gene of Saccharomyces cerevisiae encodes the $\Delta 9$ fatty acid desaturase and can be functionally replaced by the rat stearoyl-CoA desaturase gene. J. Biol. Chem. 265, 20144-20149

42 Tsai, Y.-Y., Ohashi, T., Wu, C.-C., Bataa, D., Misaki, R., Limtong, S. and Fujiyama, K. (2019) Delta-9 fatty acid desaturase overexpression enhanced lipid production and oleic acid content in Rhodosporidium toruloides for preferable yeast lipid production. J. Biosc. Bioeng. 127, 430-440 https://doi.org/10.1016/j.jbiosc.2018.09.005

43 Domergue, F., Abbadi, A. and Heinz, E. (2005) Relief for fish stocks: Oceanic fatty acids in transgenic oilseeds. Trends Plant Sci. 10, 112-116 https://doi.org/10.1016/j.tplants.2005.01.003

44 Miyazaki, M., Bruggink, S. M. and Ntambi, J. M. (2006) Identification of mouse palmitoylcoenzyme A $\Delta$ 9-desaturase. J. Lipid Res. 47, 700-704 https://doi.org/10.1194/jlr.C500025JLR200

45 Hong, M., Zilinskas, B. A., Knipple, D. C. and Chin, C.-K. (2004) cis-3-Hexenal production in tobacco is stimulated by 16-carbon monounsaturated fatty acids. Phytochemistry 65, 159-168 https://doi.org/10.1016/j.phytochem.2003.10.013

46 Wang, C., Chin, C.-K. and Gianfagna, T. (2000) Relationship between cutin monomers and tomato resistance to powdery mildew infection. Physiol. Mol. Plant Pathol. 57, 55-61 https://doi.org/10.1006/pmpp.2000.0279 
47 Xing, J. and Chin, C.-K. (2000) Modification of fatty acids in eggplant affects its resistance to Verticillium dahliae. Physiol. Mol. Plant Pathol. 56, 217-225

https://doi.org/10.1006/pmpp.2000.0268

48 Tugizimana, F., Steenkamp, P. A., Piater, L. A. and Dubery, I. A. (2014) Multi-platform metabolomic analyses of ergosterol-induced dynamic changes in Nicotiana tabacum cells. PLoS One 9, e87846 https://doi.org/10.1371/journal.pone.0087846

49 Rossard, S., Roblin, G. and Atanassova, R. (2010) Ergosterol triggers characteristic elicitation steps in Beta vulgaris leaf tissues. J. Exp. Bot. 61, 1807-1816 https://doi.org/10.1093/jxb/erq047

50 Yang, J.-O., Nakayama, N., Toda, K., Tebayashi, S. and Kim, C.-S. (2014) Structural determination of elicitors in Sogatella furcifera (Horváth) that induce Japonica rice plant varieties (Oryza sativa L.) to produce an ovicidal substance against S. furcifera eggs. Biosci. Biotechnol. Biochem. 78, 937-942 https://doi.org/10.1080/09168451.2014.917266 
bioRxiv preprint doi: https://doi.org/10.1101/2020.01.13.901264; this version posted January 13,2020 . The copyright holder for this preprint (which was not certified by peer review) is the author/funder. All rights reserved. No reuse allowed without permission.

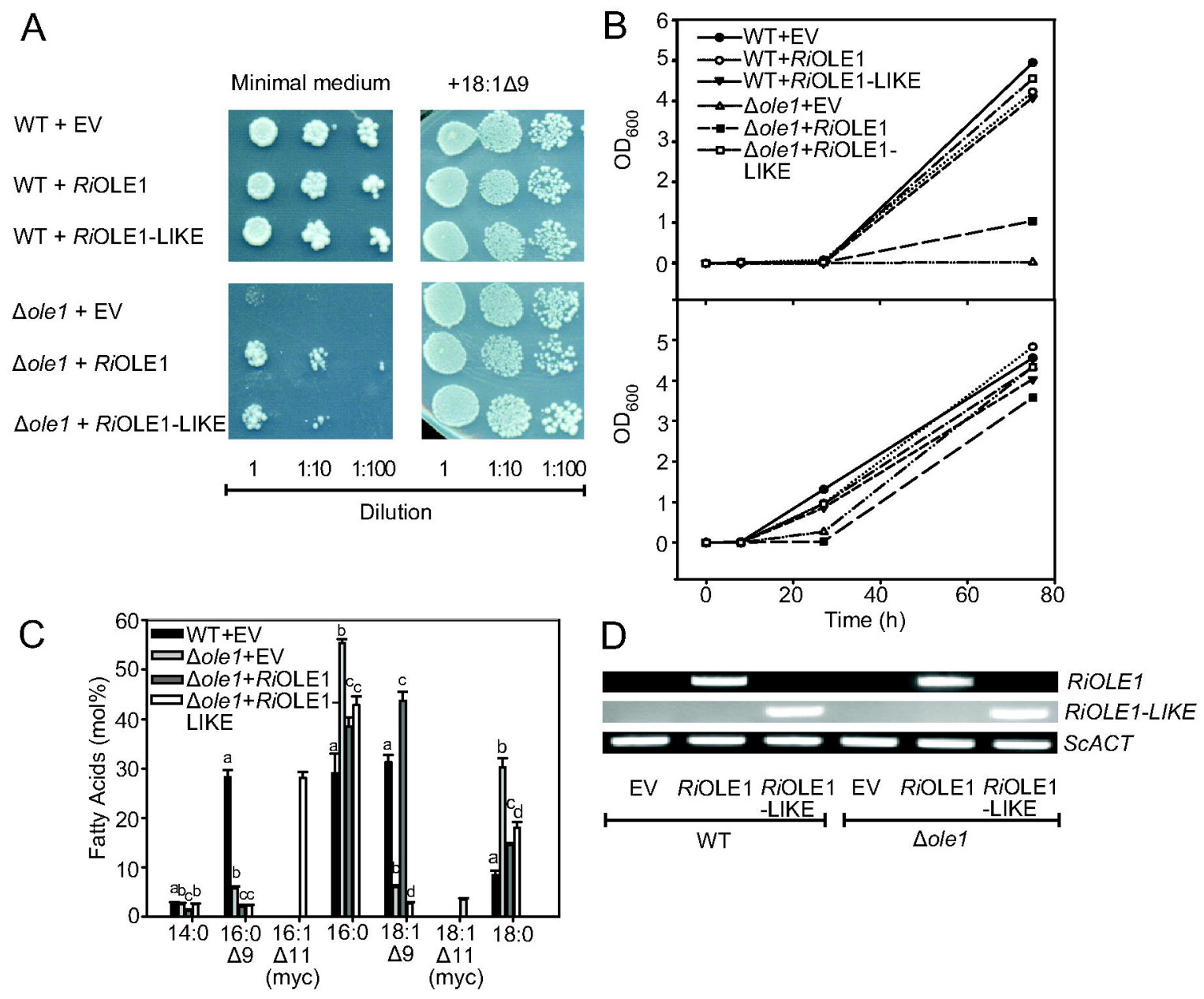

Figure 1 
bioRxiv preprint doi: https://doi.org/10.1101/2020.01.13.901264; this version posted January 13,2020 . The copyright holder for this preprint (which was not certified by peer review) is the author/funder. All rights reserved. No reuse allowed without permission.

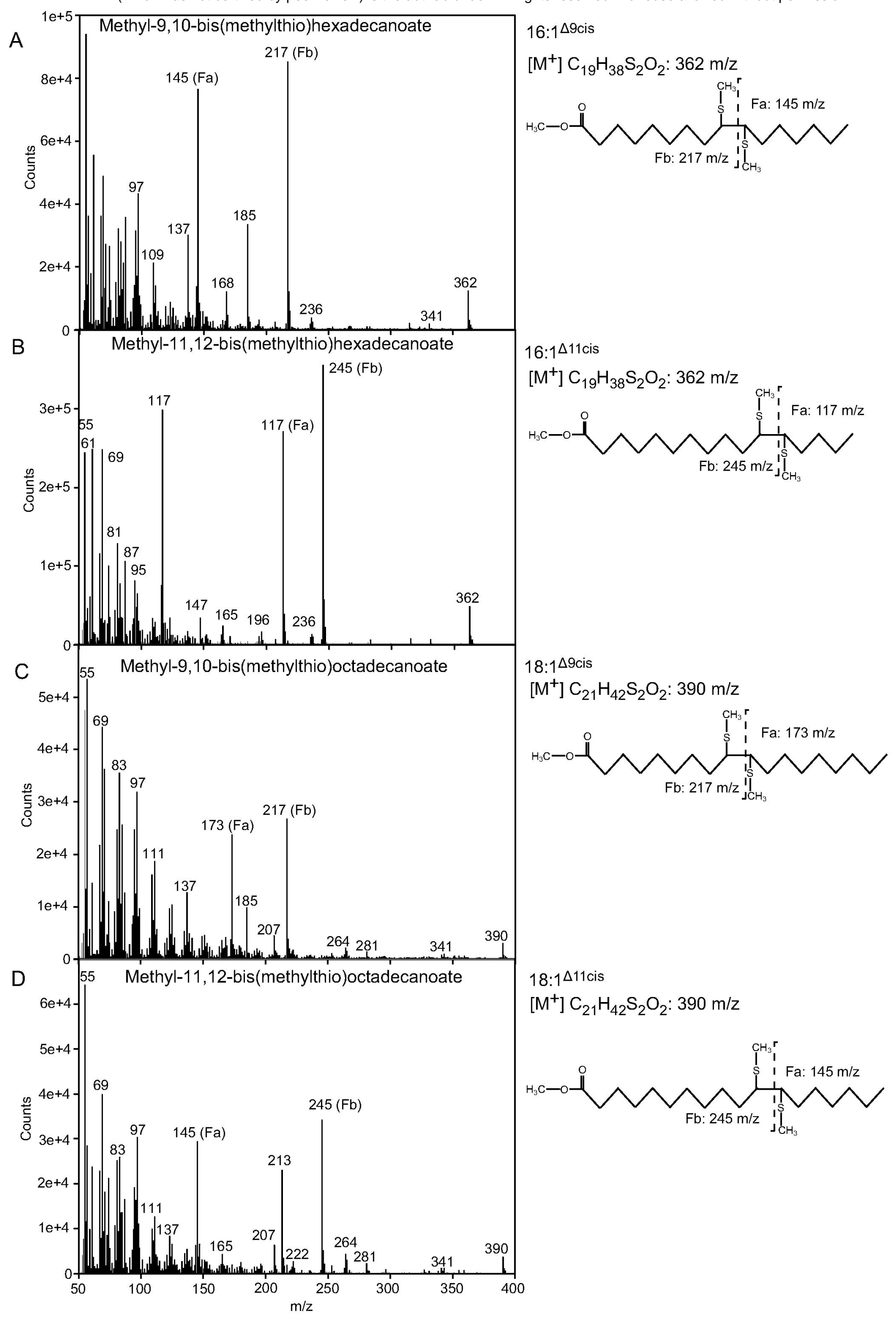

Fgiure 2 

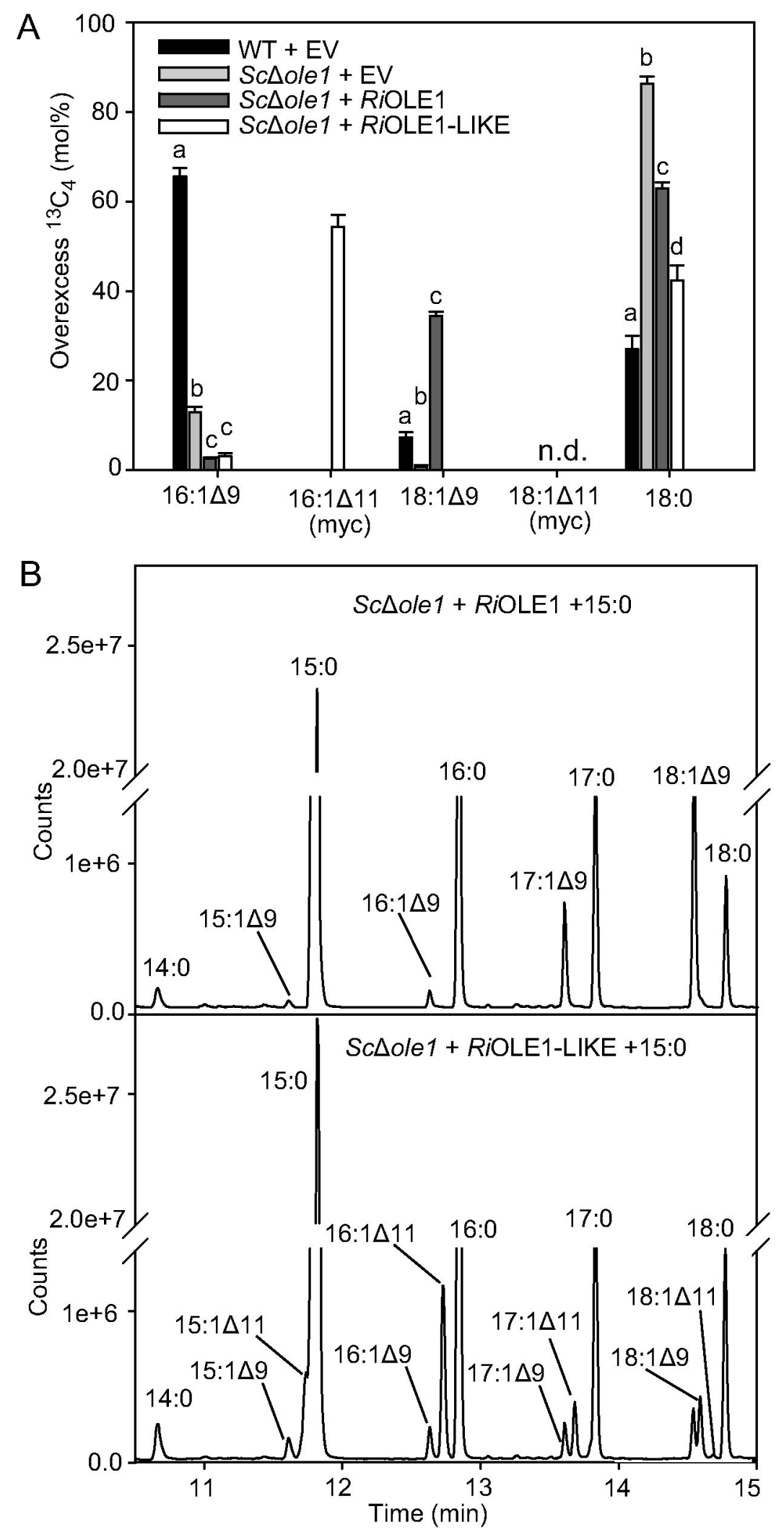

Figure 3 

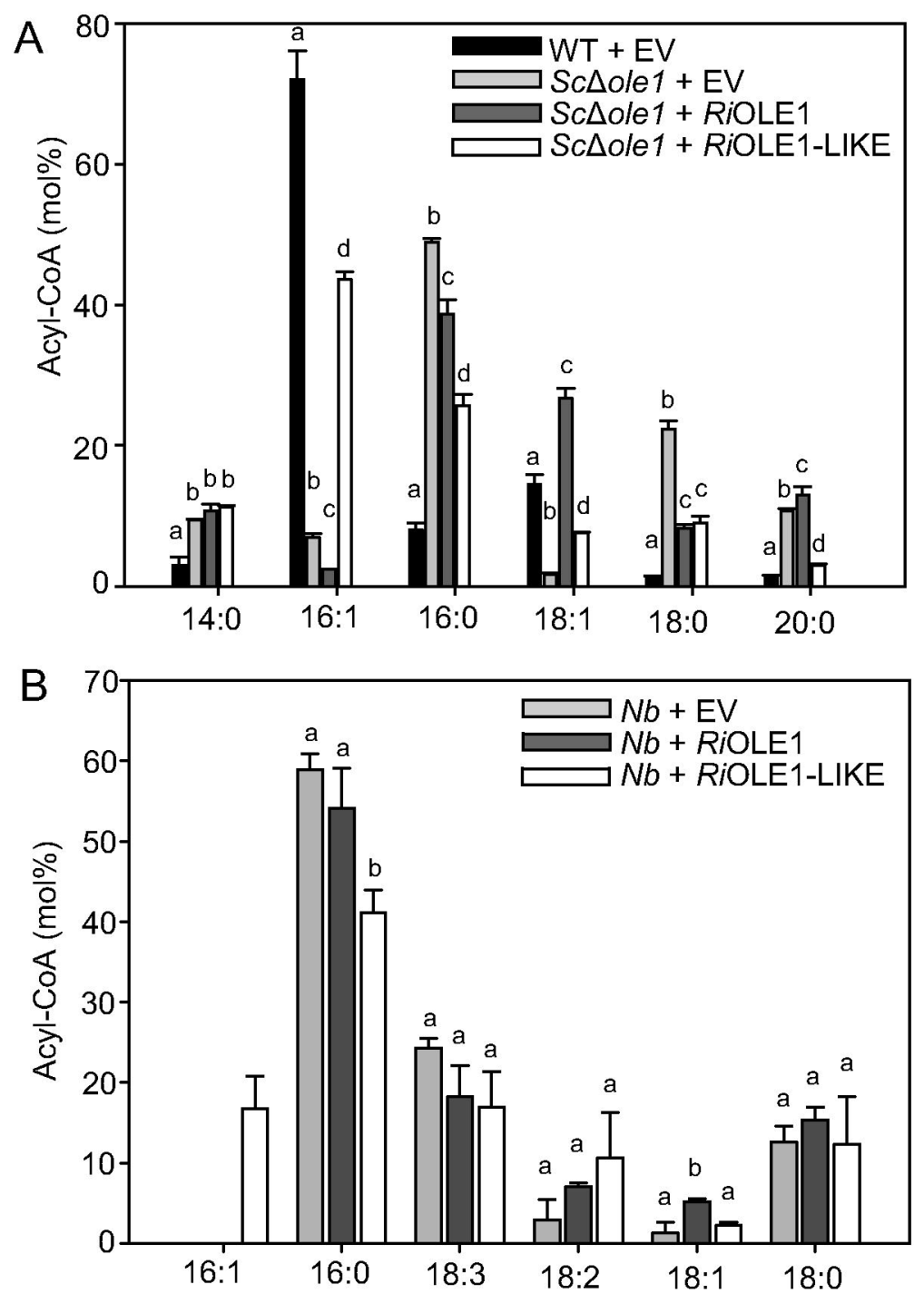

Figure 4 


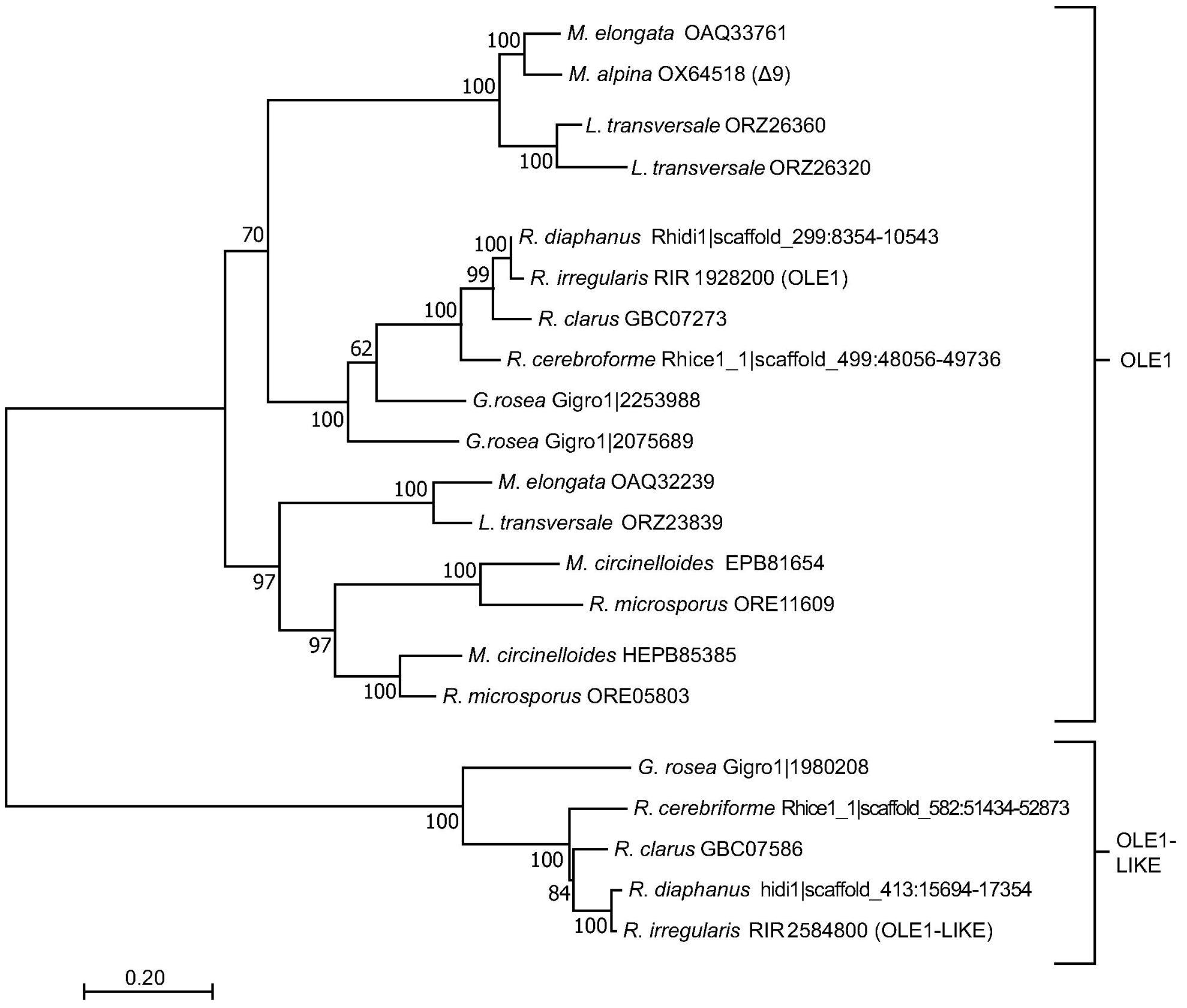

Figure 5 